\title{
Innominate Artery Cannulation Access in Pediatric Patients Undergoing Redo Sternotomy
}

\author{
Lydia Ran1, John Schultz², Jeeni Patel2, Randy Stevens',2, Achintya Moulick,2, Vicki Mahan1,2 \\ ${ }^{1}$ Drexel University College of Medicine, Philadelphia, PA, USA \\ ${ }^{2}$ Department of Cardiothoracic Surgery, St. Christopher's Hospital for Children, Philadelphia, PA, USA \\ Email: vicki.mahan@tenethealth.com
}

How to cite this paper: Ran, L., Schultz, J., Patel, J., Stevens, R., Moulick, A. and Mahan, V. (2016) Innominate Artery Cannulation Access in Pediatric Patients Undergoing Redo Sternotomy. World Journal ot Cardiovascular Surgery, 6, 112-116. http://dx.doi.org/10.4236/wjcs.2016.69018

Received: August 2, 2016

Accepted: September 4, 2016

Published: September 7, 2016

Copyright $\odot 2016$ by authors and Scientific Research Publishing Inc. This work is licensed under the Creative Commons Attribution International License (CC BY 4.0).

http://creativecommons.org/licenses/by/4.0/

\begin{abstract}
Redo sternotomy in pediatric patients can be complicated due to the unsuitability of many arterial cannulation sites for the pediatric population. Innominate artery cannulation provides a safe and easily reproducible alternative and prevents many of the disadvantages seen in femoral and axillary artery cannulation. Its use in pediatric cardiac surgery has seen a rise [1]. Herein, we describe the technique for innominate artery cannulation in pediatric patients undergoing redo sternotomy and review our experience with the technique.
\end{abstract}

\section{Keywords}

Reentry Sternotomy, Redo Sternotomy, Cannulation for Cardiopulmonary Bypass, Aortic Cannulas

\section{Introduction}

Pediatric patients with complex congenital heart disease may require redo sternotomy. Surgical access can be challenging, time-consuming, and associated with the risk of major bleeding due to tissue scarring and adhesions between the heart and other structures in the mediastinum. A well-thought out preoperative plan can reduce the incidence of these injuries [2]. Particularly important to this surgery is the minimization of arterial and neurological complications [3]. A variety of cannulation sites are used to achieve this but are not always easily accessible or reliable. The ascending aorta is the standard cannulation site. Axillary artery cannulation requires additional time as well as presenting the risk of brachial plexus damage, seromas, and limb ischemias [4]. Due to small vessel size, femoral cannulation is unsuitable for infants under $15 \mathrm{~kg}$ and, for larger patients, can result in hematomas, seromas, neuropathies, limb ischemia, and li- 
mited mobility [5]. Thus, there is a need to develop a safe approach to achieving routine arterial access in pediatric patients undergoing redo sternotomy. Innominate artery cannulation during redo sternotomy, first introduced by Asou et al., has seen an increase in its use for patients with congenital heart defects [6]. Potential benefits include avoidance of cannulating the ascending aorta which is often adhered to the sternum and prevention of a second incision. Herein, we describe the technique and our results of innominate artery cannulation in pediatric patients undergoing redo sternotomy. Institutional Review Board approval was granted in August 2015 for this retrospective review of all patients undergoing innominate artery cannulation during reentry sternotomy for congenital heart disease.

\section{Description of Technique}

A preoperative chest X-ray or angiogram is reviewed to determine the relationship of the aorta to the posterior sternum. Based on the lateral film, if the heart is adhered to the sternum, the right common carotid or innominate artery is isolated prior to sternotomy. An arterial cannula size is chosen which best meets vessel size and flow requirements. The innominate artery represents an equivalent caliber vessel for aortic cannulation and often the arterial cannula does not need to be downsized.

The chest is entered through the previous sternotomy incision. The incision is extended to the medial aspect of the right sternocleidomastoid muscle, and the common carotid artery or innominate artery is isolated. The innominate artery is dissected until its bifurcation is identified. A tourniquet is placed loosely around the origin of the innominate artery. The remaining brachiocephalic vessels are isolated. A purse string suture is placed at the site chosen for cannulation on the innominate artery. After heparinization, an 11 blade is used to make an arteriotomy at the chosen cannulation site. The arterial cannula is introduced into the innominate artery and advanced towards the aorta. The tourniquet is tightened and a tie is used to secure the cannula to the tourniquet. The arterial cannula is de-aired and connected to the arterial line of the cardiopulmonary bypass (CPB) circuit. Arterial pulsatility is confirmed on the CPB circuit to ensure proper lumen placement of the cannula. After a venous cannula is inserted and an adequate activated clotting time ( $>480$ seconds) is achieved, CPB may be initiated. Direct cannulation is done without use of a polytetrafluoroethylene graft.

\section{Results}

From August 2009 to December 2015, eight patients underwent innominate artery cannulation during a redo cardiac surgery, five of which underwent their second median sternotomy, two their third, and one their fourth. As seen in Table 1, patients underwent redo sternotomy for a variety of congenital heart procedures for which innominate artery cannulation for CPB was necessary. The mean CPB time was 118 minutes and mean cross-clamp time was 30.5 minutes. Deep hypothermic circulatory arrest was used in three patients. Required flows during bypass were easily achieved and no mortality or change in clinical neurological status was observed (Table 2). 
Table 1. Operative data describing re-do surgery procedures done. ASD: atrial septal defect; CHB: complete heart block; HLHS: hypoplastic left heart syndrome; L-TGA: levo-transposition of great arteries; MPA: main pulmonary artery; PA: pulmonary artery; PAB: pulmonary artery banding; PDA: patent ductus arteriosus; PPM: pacemaker; PVR: pulmonary vascular resistance; RPA: right pulmonary artery; RV: right ventricle; RVOT: right ventricular outflow tract; VSD: ventricular septal defect.

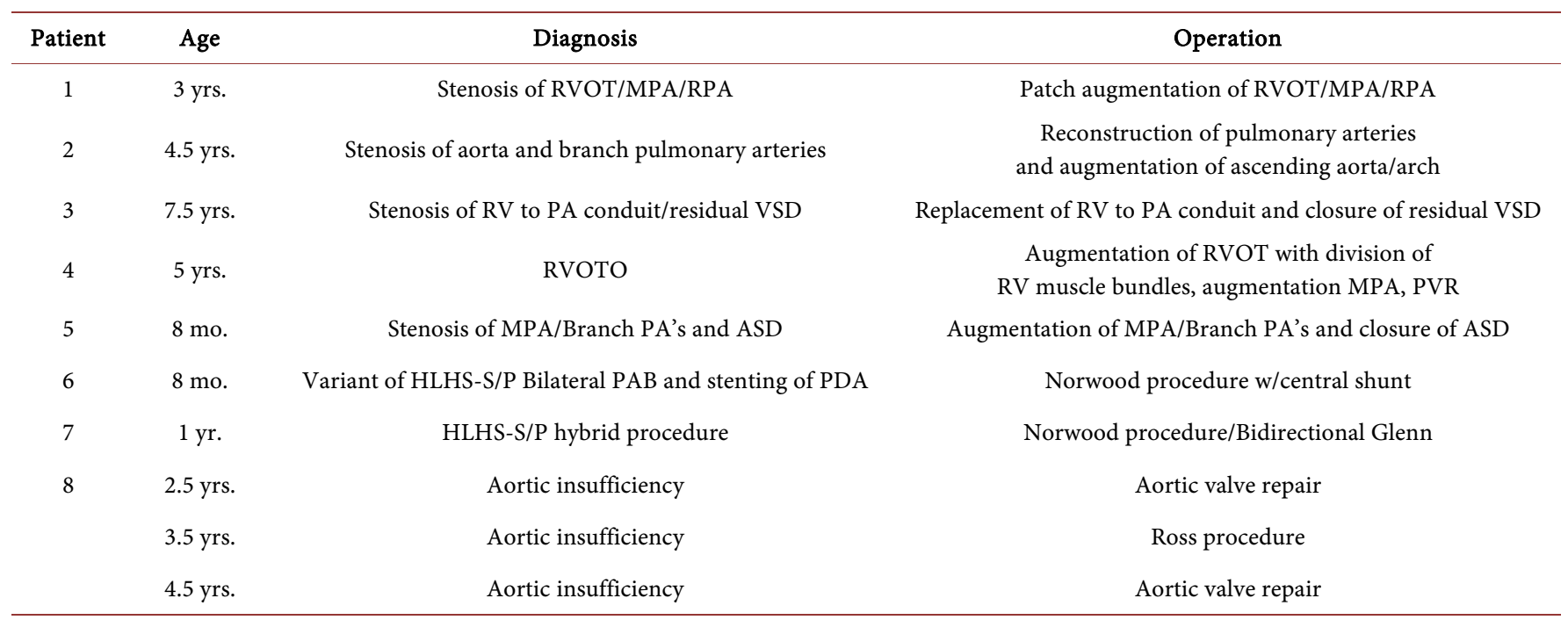

Table 2. Flows achieved and neurologic status. BSA: body surface area.

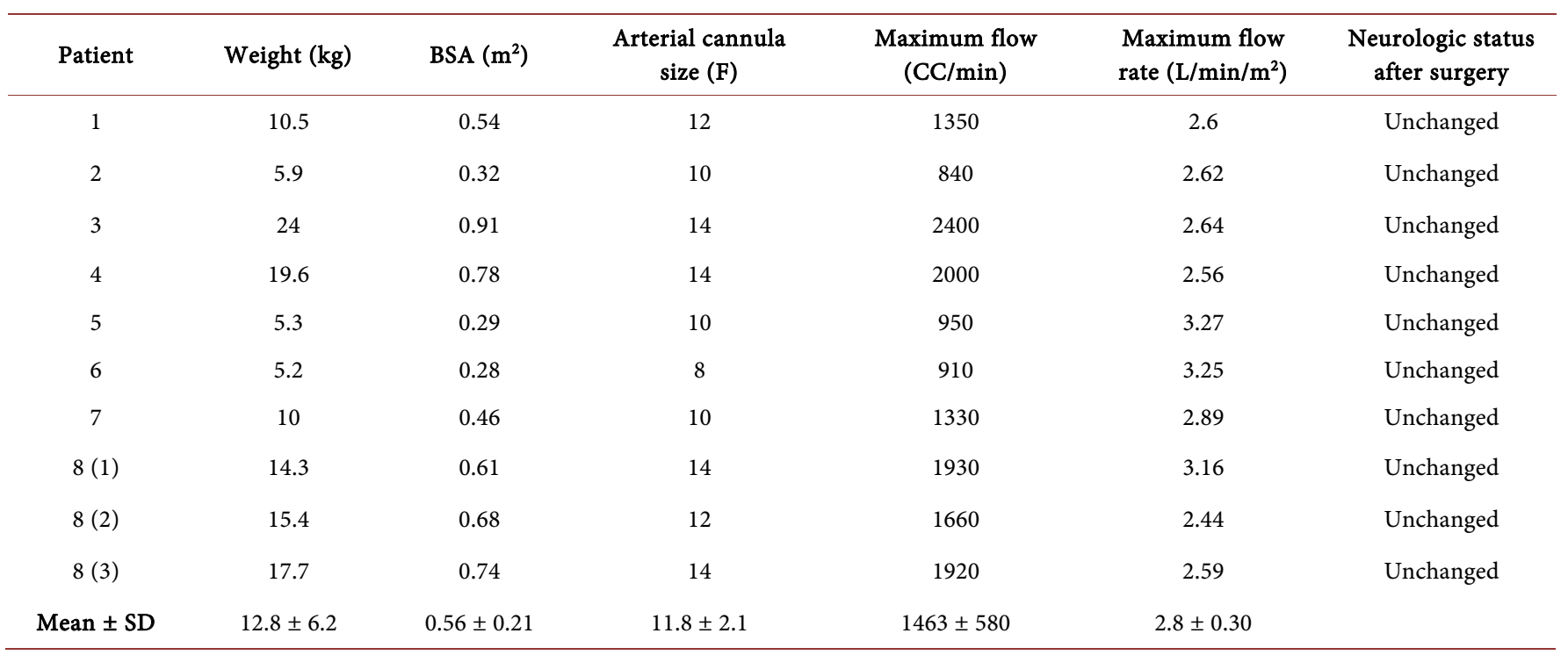

\section{Discussion}

While there are a number of sites that can be utilized for arterial cannulation, many of these may be inappropriate for small pediatric patients. The innominate artery has increased in popularity as a cannulation site [7] [8]. The safety and efficacy of innominate artery cannulation was demonstrated by Nasirov et al. in a retrospective review of 42 pediatric patients undergoing aortic arch surgery [1]. There were no operative mortalities or evidence of clinical neurologic injury. Redo sternotomy in cardiac surgery carries a substantial amount of risk in pediatric patients and can be associated with cata- 
strophic injuries to mediastinal structures. Preoperative planning, including arterial cannulation access for $\mathrm{CPB}$, is essential for the reduction of morbidity and mortality.

We have found that innominate artery cannulation offers a safe and effective method for arterial cannulation in patients undergoing redo sternotomy. Our clinical experience with 8 patients demonstrated that adequate flow was achieved and no neurologic status change was found post-surgery. To our knowledge, no one has demonstrated the success of innominate artery cannulation in the variety of congenital heart disease procedures seen here. Innominate artery cannulation prevented the need for a second incision and avoided the possibility of neuropathic injuries or limb ischemia seen with femoral and axillary artery cannulation. Redo sternotomy may be complicated during entrance into the mediastinum due to adherence of structures to the posterior sternum following the first surgery. Innominate artery cannulation may be difficult with highly tortuous vessels [4]. In larger patients and in the adults, the axillary artery serves as a viable arterial cannulation site as an alternative to the innominate artery but cannot be used in smaller pediatric patients [9] [10].

\section{Conclusion}

Statistical analysis is limited with our sample size and a broader review with greater statistical power is needed. A comparison of complications between cannulation sites and a more thorough work-up of neurological status would provide the next steps to determine the long-term outcomes of this technique. However, the results from this study demonstrate the innominate artery as a simple and reproducible access option for cannulation in the high risk population of pediatric patients requiring redo sternotomy.

\section{Disclosures}

All authors declare that there is no conflict of interest in this article.

\section{References}

[1] Nasirov, T., Mainwaring, R.D., Reddy, V.M., Sleasman, J., Margetson, T. and Hanley, F.L. (2013) Innominate Artery Cannulation and Antegrade Cerebral Perfusion for Aortic Arch Reconstruction in Infants and Children. World Journal for Pediatric and Congenital Heart Surgery, 4, 356-361. http://dx.doi.org/10.1177/2150135113497767

[2] Imran Hamid, U., Digney, R., Soo, L., Leung, S. and Graham, A.N. (2015) Incidence and Outcome of Re-Entry Injury in Redo Cardiac Surgery: Benefits of Preoperative Planning. European Journal Cardio-Thoracic Surgery, 47, 819-823. http://dx.doi.org/10.1093/ejcts/ezu261

[3] Hammel, J.M., Deptula, J.J., Siecke, R., Abdullah, I. and Duncan, K.F. (2013) Descending Aortic and Innominate Artery Cannulation for Aortic Arch Repair with Mildly Hypothermic Continuous Cardiopulmonary Bypass in Infants and Children. World Journal for Pediatric and Congenital Heart Surgery, 4, 418-421. http://dx.doi.org/10.1177/2150135113492346

[4] Garg, V., Tsirigotis, D.N., Dickson, J., et al. (2014) Direct Innominate Artery Cannulation for Selective Antegrade Cerebral Perfusion during Deep Hypothermic Circulatory Arrest in Aortic Surgery. The Journal of Thoracic and Cardiovascular Surgery, 148, 2920-2924. 
http://dx.doi.org/10.1016/j.jtcvs.2014.07.021

[5] Maxwell, B. and Wise-Faberowski, L. (2014) Management of High-Risk Reentry Sternotomy in an Infant for Repair of a Giant Pseudoaneurysm of the Right Ventricular Outflow Tract. Annals of Cardiac Anaesthesia, 17, 59-61.

http://dx.doi.org/10.4103/0971-9784.124145

[6] Asou, T., Kado, H., Imoto, Y., et al. (1996) Selective Cerebral Perfusion Technique during Aortic Arch Repair in Neonates. Annals of Thoracic Surgery, 61, 1546-1548. http://dx.doi.org/10.1016/0003-4975(96)80002-S

[7] Huang, F.J., Wu, Q., Ren, C.W., et al. (2010) Cannulation of the Innominate Artery with a Side Graft in Arch Surgery. Annals of Thoracic Surgery, 89, 800-803.

http://dx.doi.org/10.1016/j.athoracsur.2009.12.005

[8] Di Eusanio, M., Dimitri Petridis, F., Folesani, G., Berretta, P., Zardin, D. and Di Bartolomeo, R. (2014) Axillary and Innominate Artery Cannulation during Sugery of the Thoracic Aorta: A Comparative Study. Journal of Cardiovascular Surgery (Torino), 55, 841-847.

[9] Yavuz, S., Goncu, M.T. and Turk, T. (2002) Axillary Artery Cannulation for Arterial Inflow in Patients with Acute Dissection of the Ascending Aorta. European Journal Cardio-Thoracic Surgery, 22, 313-315. http://dx.doi.org/10.1016/S1010-7940(02)00249-X

[10] Calvaruso, D., Voisine, P., Mohammadi, S., Dumont, E. and Dagenais, F. (2012) Axillary Artery Cannulation. Multimedia Manual Cardio-Thoracic Surgery, 2012, mms004. http://dx.doi.org/10.1093/mmcts/mms004

\section{Submit or recommend next manuscript to SCIRP and we will provide best service for you:}

Accepting pre-submission inquiries through Email, Facebook, LinkedIn, Twitter, etc. A wide selection of journals (inclusive of 9 subjects, more than 200 journals)

Providing 24-hour high-quality service

User-friendly online submission system

Fair and swift peer-review system

Efficient typesetting and proofreading procedure

Display of the result of downloads and visits, as well as the number of cited articles

Maximum dissemination of your research work

Submit your manuscript at: http://papersubmission.scirp.org/ 